\title{
THE PERSONALITY PROFILE OF POLICE RECRUITS WHO ARE HIGH ON ANXIETY
}

\author{
BURGERT VAN JAARSVELD \\ JOHANN M SCHEPERS \\ annetjieb@uj.ac.za \\ Dept of Human Resource Management \\ University of Johannesburg
}

\begin{abstract}
The principal objective of the study was to determine the personality profile of police recruits who are high on anxiety. A secondary objective was to determine whether there are gender and ethnic differences in the levels of anxiety of those police recruits. To investigate the stated objectives the NEO Personality Inventory, Locus of Control Inventory and the IPAT Anxiety Scale were applied to 487 police recruits. Complete records were obtained for 259 participants. In comparing the personality profiles of participants who are high on anxiety and those who are low, it turned out that the biggest differences were in respect of Neuroticism, External Locus of Control and Agreeableness.
\end{abstract}

Key words: Personality profile, neuroticism, external control, agreeableness, anxiety, post traumatic stress-disorder, logistic regression.

As South Africans are becoming increasingly concerned about the critical role of the police in enforcing the rules that regulate life in our country, or the lack thereof, a growing interest is also developing in the characteristics and behaviour of police personnel. The ability of police members to fulfil the responsibilities of upholding the standards of society and of imposing its penalties may depend upon their personal values, personality and activities. Hence, the examination of those factors along with such matters as police recruitment and socialisation is an important prerequisite to the investigation of police practices. Without an understanding of the attributes of law enforcement personnel and the way in which they affect the performance of law enforcement duties, it is difficult to appreciate the broad implications of police actions in the maintenance of social order. According to Rothmann and Storm (2003) it is important to have a productive and healthy police force that serves as a contributor to the economic growth in South Africa.

Eber (1991) re-examined several large-scale studies done on law enforcement candidates. He collected data in respect of more than 15000 police candidates. The main measures were the two parts of the Clinical Analysis Questionnaire (CAQ) (Krug, Cattell \& IPAT, 1980) where Part I consists of the 16 Personality Factor Questionnaire Scales, and Part II consists of 12 measures of psychopathology. The most striking finding was the clear personality profile of law enforcement candidates in the United States. Their personality profiles were characterised by a strong pattern of Low Anxiety, Control and Tough Poise.

Lorr and Strack (1994) administered the same instrument and used cluster analysis to examine the personality profile of police applicants. Cluster analysis consists of grouping objects based on their similarity in certain characteristics, and creating certain subgroups or clusters. The aforementioned study revealed the existence of two different personality profiles. The majority group, very similar to what Eber had described as "good policemen" (Eber, 1991), was characterised by a high level of self-control, independence, extraversion and emotional stability (low neuroticism). The second group, similar to Eber's "bad policemen", did not differ much from the aforementioned group in terms of independence, however, they did manifest a low level of control, introversion and a much higher level of anxiety.

Both of the abovementioned studies came to the same conclusion, namely, that there are some personality characteristics which apply to successful candidates in the police force.
In a study of 120 police officers by Knoetze and de Bruin (2001), it is stated that high scores on trait anxiety form the basis of a number of criteria of psychopathology and that this specifically forms an integral component of Post Traumatic Stress Disorder (PTSD). Hence, it is likely that police candidates with high scores on trait anxiety will be more likely to develop PTSD than those with low anxiety. A distinction between state and trait anxiety has become commonplace (Spielberger, 1972, 1983). State anxiety is defined as an unpleasant emotional arousal in the face of threatening demands or dangers, thus being circumstantial. Trait anxiety, on the other hand, reflects the existence of stable individual differences in the tendency to respond with state anxiety in the anticipation of threatening situations. It is expected that individuals with low trait anxiety will be more resistant to the negative effects of unusual situations than individuals with high anxiety. Police officers with high scores on anxiety and neuroticism will be more prone to suffer the negative consequences of stressful situations and to develop PTSD. Knoetze and De Bruin (2001) further stipulate that prospective candidates should be assessed and those with high scores on trait anxiety should not be considered for operational police activities because they will be more prone to develop PTSD.

Anxiety and PTSD can have a devastating effect on the victim's life as well as the lives of those people sharing his or her life. There have been several reports of suicidal behaviour, violence, depression, breakdown of family life, alcoholism and work incompetence by both researchers and police authorities. In the literature that follows it will become clear that it is of fundamental importance to get a better understanding of such a person's personality in order to assist in creating a better support system for him/her.

Carson, Butcher and Mineka (1996, p. 128) maintain that the continuous perception of threat of a psychological nature leads to an increasingly narrow perceptual field and rigid cognitive processes. It thus becomes difficult for the person to see the situation objectively or to perceive the alternatives that are actually available. This often appears to be part of suicidal behaviour. This is supported by the study of Knoetze and de Bruin (2001) where it was determined that the number of year's service by police candidates positively correlates with the development of PTSD in the presence of high anxiety.

Barlow and Durand (1999, p. 138) describe PTSD as a severe, long-lasting emotional disorder in persons who have experienced emotional or physical stress that was of a magnitude which 
would be extremely traumatic for virtually anyone. Examples of such traumata include combat experience, natural catastrophes, assault and serious accidents (e.g., automobile accidents, building fires). It is further speculated that the most likely events predisposing to the development of PTSD are situations of trauma and certain personality traits.

In a study done by Sims and Sims (1998) of 70 police officers in the UK (59 men and 11 women) it was found that PTSD was associated with higher scores on rating scales of both depressive and anxiety symptomatology. Alcohol consumption increases and social functioning at work and in marriage deteriorates with PTSD. The findings of Sims and Sims (1998) are similar to those of Habermann (1997) who found that long-term exposure to stress and trauma also leads to PTSD symptomatology, again supported by Knoetze and de Bruin (2001), and to secondary psychopathology, like addiction.

A similar study to the above two was done in the Scottish police force (Biggam, Power, MacDonald, Carcary, \& Moodley, 1997) where it was found that PTSD is associated with symptoms of anxiety, somatic complaints, severe depression and social dysfunction. In a study by De Jong, Timmerman, and Emmelkamp in the Netherlands (1996), wherein they investigated the Survey of Recent Life Experiences for construct validity and possible associations with social support and somatic complaints, the authors came to the same conclusions as Biggam et al. They state that there was a lower occurrence of PTSD if there were sufficient support groups to provide counselling for police officers who experienced traumatic experiences. These findings agree with the findings of Barlow and Durand (1999, p. 142) where they state that "in examining the factors contributing to who develop PTSD and who do not, it was found that social support was a very protective factor." Brown and Grover (1998) in a study of 594 police officers found that the officers most at risk are those with a profile that exhibits a high negative attitude towards emotional expression (Introversion) and low levels of social support.

Persons with PTSD have certain personality traits in common, besides the obvious criteria discussed in the DSM-VI. Wilson, Poole and Trew (1997) found this in a study of all police officers who were involved in terrorist incidents in Ireland between July 1993 and January 1994. They indicate that this would be an avenue for future research. They also found that $5 \%$ of the sample would meet the current criteria of PTSD. In addition, $25 \%$ of the officers reported symptoms consistent with at least mild to moderate depression. In the group with PTSD, the levels of depression were very high and were associated with high anxiety.

In a study done by Wearing and Hart (1996a), involving 676 police officers, they came to the following conclusions:

- PTSD is the result of a number of variables;

- stable personality characteristics are the strongest determinants of police officers' psychological well-being;

- researchers should provide policy makers with information about the causes and consequences of PTSD; and

- in terms of prevention, it is important to develop a supportive climate and to identify high-risk persons at an early enough stage.

Wearing and Hart (1996b) speculate that PTSD is one of the most common and debilitating psychological occurrences in the police force. They further suggest that it is the one biggest cause of depression, alcoholism, and suicide for law enforcement officers. It is not usual for law enforcement officers to seek psychological help. Wearing and Hart (1996) maintain that appropriate psychological measures should be developed based on personality and cognitive traits, in order to diagnose those at risk at recruitment stage.

According to Bartol (1996) there is a definite need for more research on anxiety and PTSD in the police force with specific reference to personality aspects. He also states that there is now more affinity towards personality assessments of police officers because of the severe psychological and physical consequences, but that little research has been done so far. McCafferty (1999, p. 179) further states that there are few statistics in the literature on personality types in the police force and that further research will help to understand police work and its effects on individuals.

According to a study by Gulle, Tredoux and Foster (1998), the South African Police Services has one of the highest rates in the world when it comes to psychopathology.

It is further important to note the context of violence in which police officials are working in South Africa. Statistics support the view that South Africa is an extremely violent country. Van Dijk (1996) indicated that over a period of five years, about 70 percent of the urban population in South Africa were victimised at least once. Being violently victimised in South Africa has become a statistically normal feature in the urban and rural setting. South African Police Service figures indicate that in 1996 there were a total of 25782 reported murders, 28516 attempted murders and 12860 car hijackings and in terms of sexual violence, there were a total of 50481 rapes. As such, the homicide rate for South Africa was estimated at about 61 per 100000 inhabitants, making it almost the highest in the world. South African children are also struck hard with violence. In 1996, 20333 crimes of a sexual nature were reported to Child Protection Units, while there were 8626 reported assaults of children.

These statistics, however, are likely to underestimate the incidence of violence since it only reflects those crimes that are reported.

\section{Post-traumatic stress disorder}

The diagnostic and Statistical Manual of Mental Disorders, fourth edition or DSM-IV (American Psychiatric Association, 1994) describes the trigger event for PTSD as exposure to a traumatic event during which one feels fear, helplessness, or horror. Afterwards, victims re-experience the event through memories and nightmares. When memories occur very suddenly and the victims find themselves reliving the event, they are having a flashback. Victims avoid anything that reminds them of the trauma. They display a characteristic restriction or numbing of emotional responsiveness, which may be very disruptive to interpersonal relationships.

The DSM-IV further states that victims unconsciously attempt to avoid the experience of emotion itself, like people with a panic disorder, since intense emotions could bring back memories of the trauma. Finally, victims typically are chronically overaroused, easily startled, and quick to anger.

As indicated in the DSM-IV, PTSD is subdivided into acute and chronic. Acute PTSD can be diagnosed between one and three months after the event/s occurred. When PTSD continues longer than three months, it is considered chronic.

Chronic PTSD is usually associated with more prominent avoidance behaviours (Davidson, Hughes, Blazer \& George, 1991), as well as with more frequent co-occurrences of additional symptomatology such as social phobia, depression and alcoholism. There is also a high occurrence of suicide as a result of PTSD. In delayed onset PTSD, individuals show few if any symptoms immediately after a trauma, but later, perhaps years afterwards, they develop full-blown PTSD. Why onset is delayed in some individuals is not yet clear (Barlow \& Durand, 1999, p. 140).

Pertinent to the revision of psychiatric categories is the comorbid relationship between PTSD, anxiety and depression. Angst and Wicki (1990) report an 81\% concordance between cases of PTSD and depression, whereas Rubin and Lesser (1990) indicate that between $20 \%$ and $90 \%$ of clients present with concomitant anxious and depressive disorders. The importance 
of this co-morbidity has been emphasised by Keller and Lavori (1990) in relation to the pathophysiology and course of the disorders and the formulation of treatment policy or prevention programmes, as well as Lomax and Pokorny (1988) in relation to suicide. Hamilton (1988), and Pollack, Otto, Rosenbaum, and Sachs (1992) have also supported the views of Keller and Lovori, and Lomax and Pokorny.

Rothmann and Storm (2003) investigated burnout in the South African Police Service and stated that in comparison with other occupations, police work is one of the most stressful, which is particularly true given the high levels of crime and violence in South Africa.

\section{Suicide in the police force}

Most American studies report higher police suicide rates in comparison to the age-matched population. A survey carried out in Germany by Schmidtke, Fricke and Lester (1999), yielded higher suicide rates for police officers in comparison to a comparable age group. The most commonly used suicide method was shooting (71\%). Hypotheses often attribute high suicide rates among police officers to higher work stress than in other professions. Other hypotheses implicate individual variables such as psychiatric illness, alcoholism, and interpersonal and marital problems. Further defined, these are secondary psychopathology because of posttraumatic stress-disorder. The findings of Shmidtke et al. (1999) are similar to those of VandenBos and Bulatao (1996), namely that suicide in the police force are very high in comparison to the general population and is the direct result of their work and being exposed to violence and trauma.

Police suicide can be minimised by identifying high-risk persons at an early stage. Case studies of officers who have committed suicide revealed that most of them had suffered form symptoms of posttraumatic stress-disorder and that alcohol consumption played a role (Violanti, 1996). Violanti also found that suicide is the result of exposure to stress and traumatic incidents in the police force.

The South African Police Service realised the urgent need for a suicide prevention programme when the suicide rate of the police force in the Free State surpassed that of all other provinces in the country in 1994. Between then and 1997 one in 365 Free State police officers killed themselves. The psychological services, social work and spiritual services of the Police Service teamed up to research the problem and found that exposure to trauma and work stress were contributory factors (Wech, 1998, p. 48). According to Violanti, Vena and Petralia (1998), suicide is one of the biggest killers of police personnel.

\section{Statement of problem}

The principal objective of the study was to determine the personality profile of police recruits who are high on anxiety. A secondary objective of the study was to determine whether there are gender and ethnic differences in the levels of anxiety. To investigate the stated objectives the following hypotheses were formulated:

H1: There is a statistically significant difference in the vector of means of the personality variables of the participants who are high and those who are low on anxiety.

H2: There is a statistically significant difference in the mean scores of the men and woman in respect of anxiety.

H3: There is a statistically significant difference in the mean scores of White Police Recruits and Black (African) Police Recruits in respect of anxiety.

The following postulates were also investigated:

Postulate 1: A single factor underlines the IPAT Anxiety Scale.

Postulate 2: The NEO Personality Inventory (NEO PI - R ${ }^{\mathrm{TM}}$ ) and Locus of Control Inventory (LCI) can be used to predict the participants' level of anxiety as measured with the IPAT Anxiety Scale.

\section{RESEARCH DESIGN}

\section{Research approach}

A quantitative approach was followed in the execution of the study. The data were collected by means of a cross-sectional field survey.

\section{Research method \\ Participants}

A convenience sample of 487 police recruits was drawn. They were tested as they entered the South African Police Force while on training at the Police College in Pretoria. The advantage of this was that they had not yet been exposed to the stresses and trauma associated with police work. No discrimination was made on the basis of gender, race, language, or age.

The participants were subjected to three different batteries of tests. Complete records were obtained for 387 recruits in respect of the IPAT Anxiety Scale, however, there were three outliers which were removed from the sample. Altogether 259 complete records were obtained in respect of the three batteries of tests that were applied.

The ages of the recruits varied from 18 to 30 years, with a mean age of 25.14 years. The gender of one case was unknown. Of the 383 cases, 90 were women and 293 were men. As far as ethnic groups are concerned, the police database indicates that of the participants in the study, 176 (45.8\%) were African, $3(0.8 \%)$ were Coloured, $18(4.69 \%)$ were Indian and 187 (48.7\%) were white.

Coloured and Indian members were excluded from the study because of their low numbers in the sample. The results obtained for them would not have been significant. Hence the sample was restricted to white and African members only.

\section{Ethical Issues}

All the research procedures followed protected the anonymity of the participants. No reference will be made to individual records and the results will only reflect group tendencies. All test scores will remain confidential.

\section{Measuring Instruments}

NEO - Personality Inventory (Revised)

The NEO Personality Inventory (NEO PI - R) was developed to measure the five major dimensions of personality viz. Neuroticism, Extraversion, Openness to Experience, Agreeableness, and Conscientiousness. According to Costa and McCrae (1992, p.44) the reliabilities of the five domains of form $S$ range from 0.86 to 0.92 . Each domain comprises six facets, and their reliabilities range from 0.56 to 0.81 (p.44). As far as convergent validities are concerned, there is an impressive list of correlations with a host of measuring instruments (p.47). The coefficients listed vary from moderate to high in magnitude.

\section{IPAT Anxiety Scale}

The IPAT Anxiety Scale is based on the 16 Personality Factor Questionnaire (16PF) of Cattell (Cattell, Cattell \& Cattell, 1993). It measures the following five factors of the 16PF:
1. IPAT - Q3:
Perfectionism (-)
2. IPAT - C:
Emotional Stability (-)
3. IPAT - L:
4. IPAT - O: $\quad$ Apprehension $(+)$
Vigilance (+)
5. IPAT - Q4: Tension (+)

According to Owen and Taljaard (1988) the reliability of the total score is 0.88 according to Kuder-Richardson Formula 20. 


\section{Locus of Control Inventory (1999)}

The Locus of Control Inventory of Schepers (1999) measures three constructs, viz. Internal Control, External Control and Autonomy. The reliabilities of the three constructs are $0.82,0.87$ and 0.88 respectively. All three scales are therefore internally highly consistent. The construct validity of the three scales has been repeatedly confirmed (Schepers, Gropp \& Geldenhuys, 2006). External Control and Internal Control are essentially uncorrelated $(\mathrm{r}=0.16)$ and not merely bipolar opposites. Autonomy and Internal Control are substantially correlated $(\mathrm{r}=0.56 ; \mathrm{p}<0.0001)$ and share $31.7 \%$ common variance of $56.3 \%$, therefore both scales make a contribution of their own (Schepers et al., 2006, p.7). As far as validity is concerned, it was found that Internal Control and Autonomy are strongly related to Psychological Wellness, and External Control negatively to Stress Management (Schepers et al., 2006, p.1).

\section{RESULTS}

To determine the dimensionality of the IPAT Anxiety Scale its scales were intercorrelated and subjected to a principal factor analysis. The matrix of intercorrelations is given in Table 1 , and the eigenvalues of the unreduced intercorrelation matrix is given in Table 2.

TABLE 1

MATRIX OF INTERCORRELATIONS OF THE IPAT-ANXIETY SCALES

\begin{tabular}{lccccc}
\hline & Q3 & C & L & O & Q4 \\
\hline IPAT Q3 & 1,000 & 0,376 & 0,300 & 0,437 & 0,553 \\
IPAT C & 0,376 & 1,000 & 0,250 & 0,404 & 0,457 \\
IPAT L & 0,300 & 0,250 & 1,000 & 0,264 & 0,370 \\
IPAT O & 0,437 & 0,404 & 0,264 & 1,000 & 0,535 \\
IPAT Q4 & 0,553 & 0,457 & 0,370 & 0,535 & 1,000 \\
\hline
\end{tabular}

Note. $\mathrm{N}=387$

TABLE 2

EIGENVALUES OF UNREDUCED INTERCORRELATION MATRIX ( 5 x 5)

\begin{tabular}{lccc}
\hline Root & Eigenvalue & \% of Variance & Cumulative \% \\
\hline 1 & 2,608 & 52,157 & 52,157 \\
2 & 0,791 & 15,829 & 67,986 \\
3 & 0,637 & 12,731 & 80,717 \\
4 & 0,557 & 11,131 & 91,848 \\
5 & 0,408 & 8,152 & 100,000 \\
\hline Trace & 5,000 & & \\
\hline
\end{tabular}

Table 1 shows that the measures are substantially correlated with one another, suggesting a one - factor - structure. Table two shows that there is only one eigenvalue greater than unity, supporting the notion of a one - factor - solution according to Kaiser's criterion (1961). Accordingly, one factor was extracted and is given in Table 3.

TABLE 3

FACTOR MATrix

\begin{tabular}{lcc}
\hline Variables & Factor & $\mathbf{h}^{2} \mathbf{j}$ \\
\hline IPAT Q4 & 0,817 & 0,667 \\
IPAT Q3 & 0,670 & 0,449 \\
IPAT O & 0,658 & 0,433 \\
IPAT C & 0,575 & 0,330 \\
IPAT L & 0,436 & 0,190 \\
\hline
\end{tabular}

From Table 3 it is clear that all five measures of the IPAT Anxiety Scale have substantial loadings on the single factor that was extracted.

Next, each of the IPAT Anxiety Scale measures were transformed to a mean of 50 and a standard deviation of 10 . The transformed scores were then summed and a total score was computed for each of the respondents. The total scores were then transformed to give a mean of 50 and a standard deviation of 10 .

To examine the shape of the distribution of total scores, a box - and - whisker diagram was prepared and is shown in Figure 1.

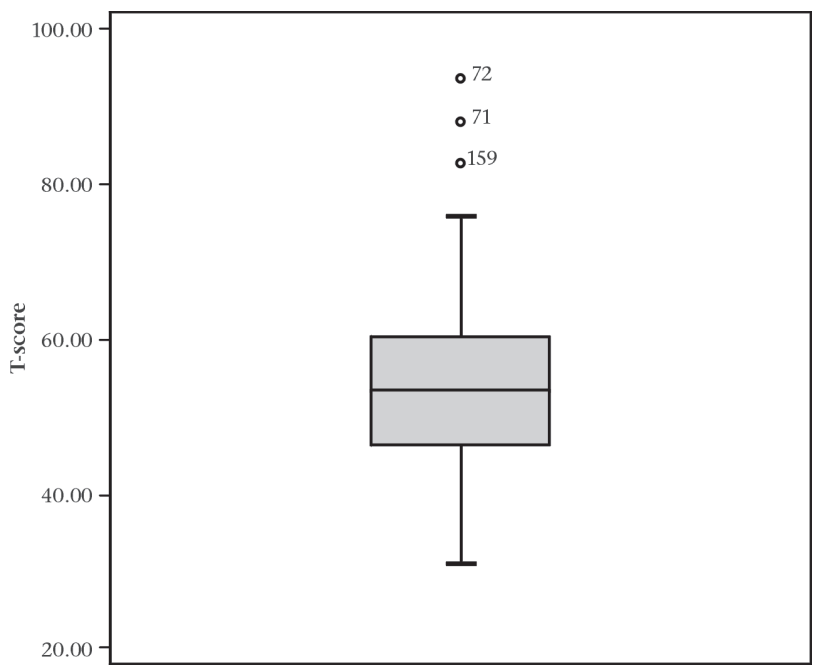

Figure 1: Box-and-whisker diagram of anxiety scores

From an inspection of Figure 1 it is clear that the "boxplot" is perfectly symmetrical, suggesting a normal distribution of points. However, there were three outliers (beyond one interquartile range from the upper whisker of the plot) that needed to be removed. After removal of the three outliers, a histogram was prepared in respect of the 384 remaining participants. The resulting histogram is shown in Figure 2.

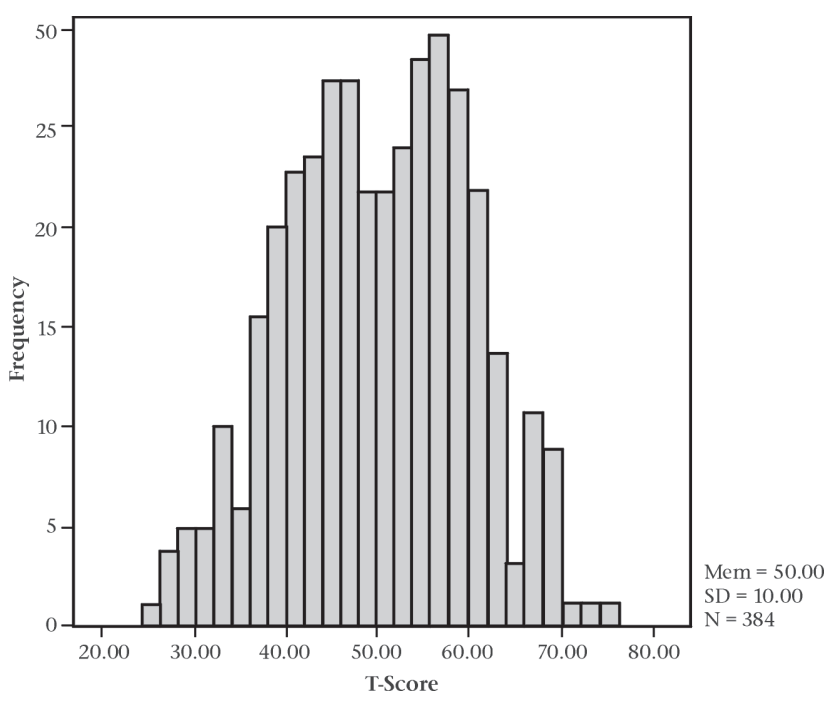

Figure 2: Histogram of anxiety scores

From Figure 2 it is clear that the distribution of the IPAT Anxiety scores is virtually a normal distribution. These scores will be used as criterion (DV) in the rest of the study.

As previously mentioned, there were complete records for 259 participants, therefore the rest of the study is based on 259 cases. 
To test the first hypothesis, two contrasting groups were formed by taking the top and bottom $25 \%$ of the distribution of anxiety scores. The means and standard deviations of these two groups, in respect of the personality variables, are given in Table 4 .

\section{TABLE 4}

MEANS AND STANDARD DEVIATIONS OF THE PERSONALITY VARIABLES IN RESPECT OF THE HIGH AND LOW ANXIETY GROUPS

\begin{tabular}{lcccccc}
\hline VARIABLES & \multicolumn{3}{c}{ HIGH GROUP } & \multicolumn{3}{c}{ LOW GROUP } \\
\cline { 2 - 7 } & MEAN & $\begin{array}{c}\text { STANDARD } \\
\text { DEVIATION }\end{array}$ & N & MEAN & $\begin{array}{c}\text { STANDARD } \\
\text { DEVIATION }\end{array}$ & N \\
\hline Neuroticism & 59,604 & 7,835 & 64 & 41,742 & 6,802 & 64 \\
Extraversion & 44,425 & 8,362 & 64 & 53,765 & 8,354 & 64 \\
Openness & 46,532 & 8,995 & 64 & 49,970 & 10,382 & 64 \\
Agreeableness & 44,801 & 7,552 & 64 & 55,309 & 9,571 & 64 \\
Conscientious- & 44,298 & 8,575 & 64 & 54,013 & 7,535 & 64 \\
ness & & & & & & \\
Autonomy & 47,262 & 9,539 & 64 & 51,641 & 8,161 & 64 \\
External Control & 56,544 & 9,797 & 64 & 44,203 & 7,833 & 64 \\
Internal Control & 47,931 & 10,116 & 64 & 52,260 & 8,298 & 64 \\
\hline
\end{tabular}

From Table 4 it is evident that there are large differences in the mean scores of the low and high groups in respect of Neuroticism, Extraversion, Agreeableness, Conscientiousness and External Control. To test for these differences, a multiple analysis of variance, followed by a series of one-way analyses of variance, were conducted.

The MANOVA indicated that there is a statistically significant difference in the vector of means of the personality variables of the participants who are high and those who are low on anxiety: Wilks' Lambda was equal to $0.003[\mathrm{~F}(8.119)=4374.643$; $\mathrm{p}=0.000]$. Hypothesis 1 is therefore supported.

To test where the differences lie, a series of one-way analyses of variance were conducted. The results are shown in Table 5.

\section{TABLE 5}

SERIES OF ONE-WAY ANALYSES OF VARIANCE IN RESPECT OF THE VARIOUS MEASURES OF PERSONALITY

\begin{tabular}{lcccccccc}
\hline $\begin{array}{l}\text { Depen- } \\
\text { dent } \\
\text { Variable }\end{array}$ & $\begin{array}{l}\text { Type III } \\
\text { Sum of } \\
\text { Squares }\end{array}$ & DF & $\begin{array}{c}\text { Mean } \\
\text { Square }\end{array}$ & F & P & $\begin{array}{c}\text { Partial } \\
\text { Eta } \\
\text { Squared }\end{array}$ & $\begin{array}{c}\text { Effect } \\
\text { Size }\end{array}$ \\
\hline $\begin{array}{l}\text { Neuro- } \\
\text { ticism }\end{array}$ & 10209,880 & 1,126 & 10209,880 & 189,684 & $0,000^{*}$ & 0,601 & 0,775 \\
$\begin{array}{l}\text { Extra } \\
\text { version }\end{array}$ & 2791,808 & 1,126 & 2791,808 & 39,968 & $0,000^{*}$ & 0,241 & 0,491 \\
$\begin{array}{l}\text { Openness } \\
\text { Agreeable- }\end{array}$ & 378,234 & 1,126 & 378,234 & 4,009 & 0,047 & 0,031 & $* * * *$ \\
ness & 3533,589 & 1,126 & 3533,589 & 47,548 & $0,000 *$ & 0,274 & 0,523 \\
$\begin{array}{l}\text { Conscien- } \\
\text { tiousness }\end{array}$ & 3020,352 & 1,126 & 3020,352 & 46,362 & $0,000 *$ & 0,269 & 0,519 \\
Autonomy & 613,662 & 1,126 & 613,662 & 7,788 & 0,006 & 0,058 & $* * * *$ \\
$\begin{array}{l}\text { External } \\
\text { Control }\end{array}$ & 4873,014 & 1,126 & 4873,014 & 61,944 & $0,000^{*}$ & 0,330 & 0,574 \\
$\begin{array}{l}\text { Internal } \\
\text { Control }\end{array}$ & 599,669 & 1,126 & 599,669 & 7,006 & 0,009 & 0,053 & $* * * *$ \\
\hline
\end{tabular}

Note. Wilks' Lambda $=0,003$

$\overline{\mathrm{F}}(8,119)=4374,643 ; \mathrm{p}=0,000]$

Adjusted probability level (Bonferroni) $=0,05 / 8$

$=0,00625$

*Statistically significant

From Table 5 it would appear that all the mean differences are statistically significant ( $\mathrm{p} \leq 0.05)$, however, in doing many comparisons the probability of falsely rejecting the null hypothesis is raised. To decrease the odds of falsely rejecting the null hypothesis when several statistical tests are done, the criterion for rejecting the null hypothesis should be adjusted. In the present case, Bonferroni's test was used. The stated criterion $(\alpha \leq 0.05)$ was divided by eight giving a probability value of 0.00625 (McGuigan, 1983, p.151). Using this probability value, three of the comparisons were judged as not significant, namely the mean differences in respect of Openness to Experience, Autonomy and Internal Control. The mean differences in respect of the other variables were highly significant. Their effect sizes $\left(\eta^{2}\right)$ varied from 0.491 to 0.775 , signifying real differences from a practical point of view.

The personality profile of participants who are high on Anxiety and those who are low on Anxiety are depicted in Figure 3.

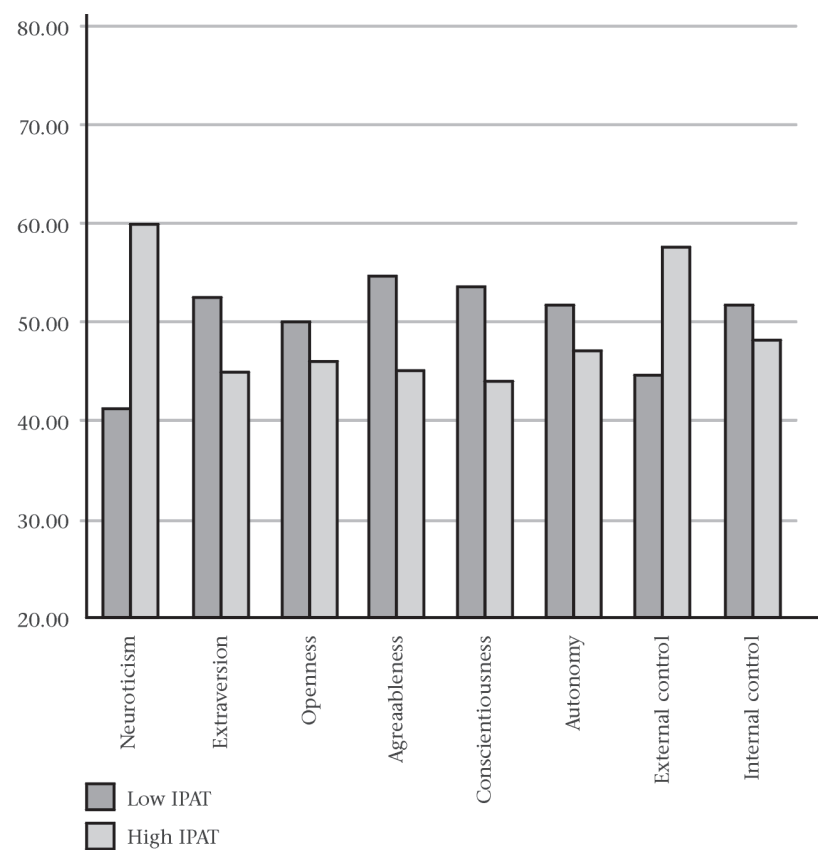

Figure 3: Personality profile of participants who are high on anxiety and those who are low on anxiety

From an inspection of Figure 3 it is clear that the biggest differences between the two groups are in respect of Neuroticism, External Control and Agreeableness. The smallest mean differences are in respect of Openness to Experience, Autonomy and Internal Control.

To test whether the men and women differ in terms of their level of anxiety, their mean scores were compared by means of a $\mathrm{t}$ - test.

The results of the t-test are given in Table 6 .

TABLe 6

T TEST: COMPARISON GROUPS IN RESPECT OF ANXIETY

\begin{tabular}{lcccccccccc}
\hline WOMEN & \multicolumn{10}{c}{ MEN } \\
\hline Mean & SD & $\mathbf{N}_{1}$ & Mean & SD & $\mathbf{N}_{2}$ & $\begin{array}{c}\text { Levene } \\
\mathbf{F}\end{array}$ & $\mathbf{p}$ & $\mathbf{t}$ & df & $\mathbf{p}$ \\
\hline 48,498 & 10,872 & 56 & 50,166 & 10,060 & 203 & 0,300 & 0,584 & $-1,080$ & 257 & 0,281
\end{tabular}

From Table 6 it is clear that there are no gender difference in respect of anxiety: $[\mathrm{t}=-1.080(\mathrm{df}=257) ; \mathrm{p}=0.281]$. Hypothesis 2 is therefore rejected.

To test Hypothesis 3, the mean scores of the Africans and Whites, in respect of anxiety, were compared by means of a t-test. The results of the comparison are given in Table 7 . 
TABLE 7

T TEST: COMPARISON OF ETHNIC GROUPS IN RESPECT OF ANXIETY

\begin{tabular}{lcccccccccc}
\hline AFRICANS & \multicolumn{1}{c}{ WHITES } \\
\hline Mean & SD & $\mathbf{N}_{1}$ & Mean & SD & $\mathbf{N}_{2}$ & $\begin{array}{c}\text { Levene } \\
\mathbf{F}\end{array}$ & $\mathbf{p}$ & $\mathbf{t}$ & $\mathbf{d f}$ & $\mathbf{p}$ \\
\hline 52,627 & 8,064 & 108 & 47,788 & 11,146 & 151 & 14,422 & 0,000 & 4,054 & 256,958 & 0,000 \\
\hline
\end{tabular}

From Table 7 it is clear that there is a statistically significant difference in respect of anxiety between the two cultural groups: $\mathrm{t}=4.054(\mathrm{df}=256,958) ; \mathrm{p}=0.000]$. Hypothesis 3 is therefore supported.

To examine Postulate 2, a step-wise regression was done with the personality variables as predictors (IV) and anxiety as criterion (DV).

As a first step in the analysis the various predictor variables and the criterion were intercorrelated. The matrix of intercorrelations is given in Table 8 .

From Table 8 it is clear that Neuroticism and External Control are substantially positively correlated with Anxiety while Agreeableness, Extraversion and Conscientiousness are moderately negatively correlated with Anxiety.
To determine the multiple correlation of the personality variables with anxiety a step-wise regression was done. The results are given in Table 9.

Table 9 shows that a multiple correlation of 0.712 was obtained. This coefficient is statistically highly significant [F (3.255) = 87.267; $p=0.000]$. This means that approximately $50 \%$ of the variance of the criterion is accounted for by the predictors (adjusted $\mathrm{R}$ - square $=0.501$ ). The following variables were included in the regression equation: Neuroticism, External Control and Agreeableness. From the beta coefficients it is clear that the biggest weight in the regression equation is carried by Neuroticism (beta coefficient is equal to 0.563). All the regression coefficients are statistically significant. Strong support for Postulate 2 was therefore found.

In order to predict the category membership of the IPAT Anxiety groups, viz. those who are low on anxiety (less than 41.656) and those who are high on anxiety (more than 57.650), a logistic regression was done. The results are given in Table 10 .

From Table 10 it is evident that according to Wald's test all the regression coefficients (B) are statistically significant. The odds of classifying a person as belonging to Group 1 (the High Group), divided by the odds of classifying him/her as belonging to Group 2 (the Low Group), is given by the coefficient indicated as Exp. (B). For instance, the odds ratio in respect of Neuroticism is

TABLE 8

MATRIX OF INTERCORRELATIONS OF THE PERSONALITY VARIABLES AND ANXIETY

\begin{tabular}{|c|c|c|c|c|c|c|c|c|c|}
\hline VARIABLES & $\begin{array}{l}\text { IPAT- } \\
\text { ANXIETY }\end{array}$ & $\begin{array}{l}\text { NEUROTI- } \\
\text { CISM }\end{array}$ & $\begin{array}{l}\text { EXTRA- } \\
\text { VERSION }\end{array}$ & OPEN-NESS & $\begin{array}{l}\text { AGREEABLE- } \\
\text { NESS }\end{array}$ & $\begin{array}{l}\text { CONSCIEN- } \\
\text { TIOUSNESS }\end{array}$ & AUTO-NOMY & $\begin{array}{l}\text { EXTERNAL } \\
\text { CONTROL }\end{array}$ & $\begin{array}{l}\text { INTERNAL } \\
\text { CONTROL }\end{array}$ \\
\hline IPAT-ANXIETY & 1,000 & 0,689 * * & $-0,343 * *$ & $-0,124^{*}$ & $-0,430^{* *}$ & $-0,410^{* *}$ & $-0,193$ ** & 0,466 * * & $-0,205$ ** \\
\hline NEUROTICISM & $0,689^{*}$ & 1,000 & $-0,506^{* *}$ & $-0,276^{* *}$ & $-0,454$ ** & $-0,663 * *$ & $-0,357$ ** & 0,494 ** & $-0,286^{* *}$ \\
\hline EXTRAVERSION & $-0,343$ ** & $-0,506^{* *}$ & 1,000 & 0,451 * * & 0,322 ** & 0,491 * * & 0,368 * * & $-0,214$ ** & $0,304^{* *}$ \\
\hline OPENNESS TO EXPERIENCE & $-0,124^{*}$ & $-0,276$ ** & 0,451 ** & 1,000 & 0,206 * * & 0,307 * * & 0,266 ** & $-0,187$ ** & $0,226^{* *}$ \\
\hline AGREEABLENESS & $-0,430$ ** & $-0,454$ ** & $0,322 * *$ & 0,206 * * & 1,000 & $0,369 * *$ & 0,010 & $-0,368$ ** & 0,218 * * \\
\hline CONSCIENTIOUSNESS & $-0,410 * *$ & $-0,663$ ** & 0,491 ** & 0,307 * * & $0,369 * *$ & 1,000 & 0,485 * * & $-0,383$ ** & $0,435^{* *}$ \\
\hline AUTONOMY & $-0,193$ ** & $-0,357$ ** & $0,368 * *$ & $0,266^{* *}$ & 0,010 & 0,485 ** & 1,000 & $-0,227 * *$ & $0,670^{* *}$ \\
\hline EXTERNAL CONTROL & $0,466^{* *}$ & 0,494 * & $-0,214$ * * & $-0,187$ * * & $-0,368^{* *}$ & $-0,383$ * * & $-0,227$ * * & 1,000 & $-0,300^{* *}$ \\
\hline INTERNAL CONTROL & $-0,205^{* *}$ & $-0,286^{* *}$ & $0,304 * *$ & 0,226 ** & 0,218 ** & $0,435^{* *}$ & 0,670 ** & $-0,300 * *$ & 1,000 \\
\hline
\end{tabular}

Note. ** Significant at the 0,01 level (2-tailed)

* Significant at the 0,05 level(2-tailed)

TABLE 9

STEPWISE REGRESSION OF PERSONALITY VARIABLES ON ANXIETY (DV) ANALYSIS OF VARIANCE

\begin{tabular}{llcrr}
\hline & $\begin{array}{l}\text { Source of } \\
\text { variation }\end{array}$ & DF & $\begin{array}{r}\text { Sum of } \\
\text { squares }\end{array}$ & $\begin{array}{c}\text { Mean } \\
\text { square }\end{array}$ \\
\hline Multiple R: 0,712 & Regression & 3 & 13712,105 & 4570,702 \\
R Square: 0,507 & Residual & 255 & 13355,960 & 52,376 \\
Adjusted R Square: 0,501 & Total & 258 & 27068,065 & \\
Standard Error of Estimate: & & & & \\
7,2371482 & & & & \\
\hline
\end{tabular}

$\mathrm{F}=87,267$

$\mathrm{p}=0,000$

VARIABLES IN THE EQUATION

\begin{tabular}{lrrrrc}
\hline Independent Variables & B & SE B & Beta & t-value & P \\
\hline Constant & 19,135 & 4,876 & & 3,924 & 0,000 \\
Neuroticism & 0,588 & 0,056 & 0,563 & 10,471 & 0,000 \\
External Control & 0,153 & 0,055 & 0,143 & 2,783 & 0,006 \\
Agreeableness & $-0,126$ & 0,052 & $-0,122$ & $-2,427$ & 0,016 \\
\hline
\end{tabular}

TABLE 10

LOGISTIC REGRESSION: VARIABLES IN EQUATION

\begin{tabular}{lcrrrrr}
\hline Variables in equation & B & SE B & Wald & df & p & Exp (B) \\
\hline Neuroticism & 0,384 & 0,080 & 22,968 & 1 & 0,000 & 1,469 \\
External Control & 0,084 & 0,040 & 4,437 & 1 & 0,035 & 1,087 \\
Constant & $-23,582$ & 4,523 & 27,183 & 1 & 0,000 & 0,000 \\
\hline
\end{tabular}

TABLE 11

Predicted Membershit CATEgory ACCORDING TO LOGISTIC REgRESSION

\begin{tabular}{lccc}
\hline \multirow{2}{*}{ OBSERVED CATEGORY } & \multicolumn{2}{c}{$\begin{array}{c}\text { PREDICTED } \\
\text { CATEGORY }\end{array}$} & \\
\cline { 2 - 3 } & $\begin{array}{c}\text { 1 Low } \\
\text { IPAT }\end{array}$ & $\begin{array}{c}\text { 2 High } \\
\text { IPAT }\end{array}$ & \\
correct \\
IPAT Groups: 1 Low IPAT (less than 41,656) & 58 & 6 & $90,6 \%$ \\
2 High IPAT (more than 57,650) & 6 & 58 & $90,6 \%$ \\
Overall percentage & & & $90,6 \%$ \\
\hline
\end{tabular}

Note. Nagelkerke R Square $=0,829$ 
1.469. There is therefore a positive relation between Neuroticism and the criterion of classification. The odds ratio in respect of External Control is just above 1.0 and signifies a weak positive relation with the criterion of classification.

In order to assess the accuracy of the regression equation in predicting the membership category of the two groups of anxiety (high vs. low), the percentage correct classifications in terms of high and low anxiety were calculated and are given in Table 11 .

From Table 11 it can be seen that the logistic model correctly classified $90.6 \%$ of the cases in respect of both the high and low group. The overall percentage of $90.6 \%$ is indeed impressive. The Nagelkerke R-square of 0.829 gives an indication of the amount of variation in the dependent variable accounted for by the model (Pallant, 2005, p.167).

The following regression equation can be used to estimate the membership category (high vs. low) of new participants:

$\mathrm{P}($ High Group $)=\frac{1}{1+\mathrm{e}^{-(\mathrm{a}+\mathrm{b} 1 \mathrm{x} 1+\mathrm{b} 2 \times 2+. . \mathrm{bkxk})}}$

where $\quad \mathrm{e}=$ napierian $\log =2.71828$

$\mathrm{a}=$ constant

$\mathrm{b}_{1}=$ regression coefficient of first variable

$b_{2}=$ regression coefficient of second variable

$b_{k}=$ regression coefficient of $k$-th variable

The following example will clarify the issue:

\section{Example}

Person A's score on Neuroticism is 60 and on External Control 70.

$$
\begin{aligned}
\mathrm{P}_{(\text {High Group })} & =\frac{1}{1+\mathrm{e}^{-(23.582+0.384 \times 60+0.084 \times 70)}} \\
& =\frac{1}{1+\mathrm{e}^{-5.338}} \\
& =\frac{1}{1+0.005} \\
& =0.995
\end{aligned}
$$

If $\mathrm{P}$ (High Group) $\geq 0.5$ classify respondent as high. If P (High Group) $<0.5$ then classify respondent as low.

Person A clearly belongs to the High Group.

By contrast Person X's score on Neuroticism is 30 and his score on External Control is 40 .

$$
\begin{aligned}
\mathrm{P}_{\text {(High Group) }} & =\frac{1}{1+\mathrm{e}^{-(23.582+0.384 \times 30+0.084 \times 40)}} \\
& =\frac{1}{1+\mathrm{e}^{-8.702}} \\
& =0.000166
\end{aligned}
$$

$\mathrm{P}$ (High Group) $<0.5$ therefore Person $\mathrm{X}$ belongs to the Low Group.

\section{DISCUSSION}

\section{The personality profile of police recruits who are high on anxiety}

The IPAT Anxiety Scale was subjected to a principal factor analysis, and yielded one factor. Next, a single score was calculated for each participant and standardised with a mean of 50 and a standard deviation of 10 . This score served as dependent variable (DV) throughout the study. To test the principal hypothesis of the study, two contrasting groups were formed by taking the top and bottom $25 \%$ of the distribution of anxiety scores. The MANOVA that was conducted indicated that there is a statistically highly significant difference in the vector of means of the personality variables of participants who are high and those who are low on anxiety.

Applying the Bonferroni test it was found that three of the eight comparisons were not significant $(p<0.006)$, namely those in respect of Openness to Experience, Autonomy and Internal Control. The biggest differences were in respect of Neuroticism, External Control and Agreeableness. The personality profiles of the two groups are depicted in Figure 3.

By means of a logistic regression it was possible to classify $90.6 \%$ of the cases as belonging to the high or low anxiety group. The best predictors here were Neuroticism and External Control.

Costa and McCrae (1992) warn that the Neuroticism scale "should not be viewed as a measure of psychopathology. It is possible to obtain a high score on the Neuroticism scale without having any diagnosable psychiatric disorder" (p.14). According to them "individuals who score low on Neuroticism are emotionally stable. They are usually calm, even-tempered, and relaxed, and they are able to face stressful situations without becoming upset or rattled" (p.15).

By contrast with the foregoing, persons who are high on External Control are "unable to manage stress in any shape or form. They are the direct antithesis of persons who are high on Internal Control and Autonomy" (Schepers, et al., 2006, p.8). From the foregoing it should be clear that persons with high scores on Neuroticism and External Control are unable to manage stress in any form without becoming very anxious.

From the study of Sims and Sims (1998) it is clear that PTSD is associated with high scores on rating scales of both depressive and anxiety symptomatology. In an earlier study, Habermann (1997) found that long-term exposure to stress and trauma also leads to PTSD symptomatology and to secondary psychopathology-like addiction. The NEO PI-R and the LCI can therefore effectively be used to screen out those candidates who would not be able to cope with high levels of stress.

\section{Gender and ethnic differences in levels of anxiety}

No difference was found in the mean scores of the men and women in the sample, in respect of levels of anxiety. However in the comparison of Africans and Whites it was found that the Africans scored higher than the Whites. This fact should be kept in mind when selecting recruits for the Police Force.

Regression of NEO PI-R and LCI were used in a step-wise regression to predict the IPAT Anxiety Scale. A multiple correlation of 0.712 was obtained, accounting for $50 \%$ of the variance of the criterion. Neuroticism, External Control and Agreeableness were included in the regression equation. This confirms the usefulness of the two instruments in identifying anxiety in the participants, and can be considered for use in the selection of police recruits. The instruments should now be applied to a much larger sample and norms should be prepared for a variety of groups.

\section{CONCLUSION}

With reference to all the negative effects as discussed previously, especially the high suicide rates among South African Police Officials it becomes increasingly important for strict selection in this regard. Members selected for operational duties should be mentally fit for both their own protection as well as those communities they are suppose to serve. It is recommended that the above factors should be included in the psychometric evaluation of new police recruits before placements. 
Weaknesses and limitation of the study includes the fact that only 259 complete records were obtained out of the 487 original participants. Ideally follow up consultations and evaluation should also have taken place which unfortunately was not possible from a logistics point of view.

Further studies should also include the administration of a post-traumatic stress diagnostic scale on the same participants from this study to determine if respondents that now suffer from PTSD have had similar characteristics in terms of Personality and Locus of Control when they entered the police force.

\section{ACKNOWLEDGEMENTS}

I herewith wish to thank the following people whose support and contributions made this study possible:

Prof. Johann Schepers for his world-class advice, encyclopaedic knowledge, ability to interpret data, his belief in the value of this study and me, for the many hours he spent assisting me and for his tremendous moral support. Thank you for always being available, even in your retirement. It really is very highly appreciated.

The South African Police Service who provided the research data and support. In particular, Anton Grobler, Deon Meiring and Riana Botha.

Dr. Ri t te Eiselen for advice concerning the statistical analysis of my data, and Anneli Hardy for all the computational work done for me. I value your help very highly.

Dr. Jopie van Rooyen \& Partners for their dedication to research and their supply of research materials and assistance to me in the scoring of tests.

My mother, Mrs. Connie Bruce for prayer and financial support.

\section{REFERENCES}

Abrams, R. (1996). Assessing personality in chronic care populations. Journal of Mental Health and Aging, 2(3), 231 $-242$.

American Psychiatric Association. (1980). Diagnostic and statistical manual of mental disorders ( $3^{\text {rd }}$ ed.). Washington, DC: Author.

Angst, J. \& Wicki, W. (1990). The Zurich study: Panic, agoraphobia and generalized anxiety disorder. Journal of Psychiatric Research, 24, $21-22$.

Barlow, D.H. \& Durand, V.M. (1999). Abnormal psychology $\left(2^{\text {nd }}\right.$ ed.). Pacific Grove, CA: International Thompson Publishing.

BArtol, C.R. (1996). Police psychology: Then, now and beyond. Criminal Justice and Behaviour, 23(1), 70 - 89.

Biggam, F.H., Power, K.G., MacDonal, R.R., Carcary, W.B., \& Moodley, E. (1997). Self-perceived occupational stress and distress in a Scottish police force. Work and Stress, 11(2), $118-133$.

Bonaruis, H., Holland, R., \& Rosenburg, S. (1981). Personal construct psychology: Recent advances in theory and practice. London: Macmillan.

Brown, J. \& Grover, J. (1998). The role of moderating variables between stressor exposure and being distressed in a sample of serving police officers. Personality and Individual Differences, 24(2), $181-185$.

Carson, R.C., Butcher J.N., \& Mineka S. (1996). Abnormal psychology and modern life (10 ${ }^{\text {th }}$ ed.). New York: Harper Collins.

Cattell, R.B., Cattell, A.K. \& Cattell, H.E. (1993). The Sixteen Personality Factor Questionnaire, (5 ${ }^{\text {th }}$ ed.). Champaign IL: Institute for Personality and Ability Testing, Inc..
Costa, P.T. \& McCrae, R.R. (1992). Revised NEO Personality Inventory (NEO PI - $R^{T M}$ ) and NEO Five - Factor Inventory (NEO - FFI). Professional manual. Florida: Psychological Assessment Resources, Inc..

Daly, R.J. (1983). Samuel Pepys and posttraumatic stress-disorder. British Journal of Psychiatry, 143, $64-68$.

Davidson, J.R.T., Hughes, D.L., Blazer, D.G., \& George, L.K. (1991). Posttraumatic stress in the community: An epidemiological study. Journal of Psychological Medicine, 21, 721 - 731.

De Jong, G.M., Timmerman, I.G.H., \& Emmelkamp, P.M.G. (1996). The survey of recent life experiences: A psychometric evaluation. Journal of Behavioural Medicine, 19(6), 529 -542 .

Dunnett, G. (1988). Phobias: a journey beyond neurosis. In F. Fransella and L. Thomas (Eds), Experiencing with personal construct psychology (pp. 319 - 328). London: Routledge \& Kegan Paul.

Eber, H.W. (1991). Good cop includes bad cop: A supplementary concept of police brutality. Paper presented at the annual meeting of the Society of Multivariate Experimental Psychology, Albuquerque, NM.

Engler, B. (1985). Personality theories: An introduction. Boston: Hopughton Mifflin.

Gukke, G., Tredoux, C., \& Foster, D. (1998). Inherent and organisational stress in the SAPS: An empirical survey in the Western Cape. The South African Journal of Psychology, 28(3), $129-134$

Habermann, G.M. (1997). Looking back and moving forward: 50 years of New Zealand psychology. Wellington, NZ: New Zealand Psychological Society, Inc.

Hamilton, M. (1988). Distinguishing between anxiety and depressive disorders. In M. Hersen and C.G. Last (Eds), Handbook of anxiety disorders (pp. 143 - 155). New York: Pergamon.

Kaiser, H.E. (1961). A note on Guttman's lower bound for the number of common factors. British Journal of Statistical Psychology, 14(1), 1.

Keller, M.B., Lavori, P.W. (1990) Natural history of panic disorder. Journal of Psychiatric Research, 24 (Suppl. 1), 75.

Kelly, G.A. (1995). The psychology of personal constructs (Vols. 1 \& 2). New York: Norton.

Kessler, R.C., Sonnega, A., Bromet, E., Hughes, M., \& Nelson, C.B. (1995). Posttraumatic stress-disorder in the national co-morbidity survey. Archives of general Psychiatry, 52, 1048 -1060 .

Knoetze, J. \& de Bruin, G. (2001). Die verband tussen trekangs, diensjare en posttraumatiese stresversteuring by polisiebeamptes. Acta Academica, 33(2), 168 - 184.

Krug, S.E., Cattell, R.B. \& IPAT (1980). Clinical Analysis Questionnaire manual, Champaigne, IL: Institute for Personality and Ability Testing.

Lazarus, R. S. (I 991). Emotion and adaptation. London: Oxford University Press.

Lomax, J.W. \& Pokorny, A.D. (1988). Suicide and anxiety. In Hersen and C.G. Last (Eds), Handbook of anxiety disorders (pp. 552 - 563). New York: Pergamon.

Lorr, M. \& Strack, S. (1994). Personality profiles of police candidates. Journal of Clinical Psychology, 50 (2), 200 - 207.

Mancuso, J.C., \& Hunter, K.V. (1983). Anticipation, motivation, or emotion: The fundamental postulate after twentyfive years. In J. Adams-Webber and J.C. Manusco (Eds), Applications of personal construct theory (pp. 73 -92). Ontario: Academic.

McCafferty, F.L. (1999). "The corruption process of a law enforcement officer": Reply. Journal of the American Academy of Psychiatry and the Law, 27(1), 179.

McGuigan, F.J. (1983). Experimental psychology: Methods of research, $\left(4^{\text {th }} \mathrm{ed}\right.$.). Englewood Cliffs, N.J.: Prentice - Hall.

Otto, M.W., Pollack, M.H., Sachs, G.S., O'Neil, C.A., \& Rosenbaum, J.F. (1992). Alcohol dependence in panic disorder patients. Journal of Psychiatric Research, 26 (1), $29-38$. 
Owen, K. \& Taljaard, J.J. (1988). Handleiding vir die gebruik van Sielkundige en Skolastiese toetse van IPEN en die NIPN. Pretoria: Raad vir Geesteswetenskaplike Navorsing.

Pallant, J. (2005). SPSS survival manual ( $2^{\text {nd }}$ ed.). London: Open University Press.

Pollack, M.H., Otto, M.W., Rosenbaum, J.F. \& Sachs, G.S. (1992). Personality disorders in patients with posttraumatic stressdisorder: Association with childhood anxiety disorders, early trauma, co-morbidity, and chronicity. Comprehensive Psychiatry, 33 (2), $78-83$.

Rothmann, S. \& Storm, K. (2003). Burnout in the South African Police Service. Poster Presented at the $11^{\text {th }}$ European Congress of Work and Organizational Psychology, Lisbon, Portugal, 14-17 May 2003.

Rubin, R.T., \& Lesser, I.M. (1990). Secondary depression in panic patients. Journal of Psychiatric Research. Journal of Psychiatric Research, 24, 78 - 79.

Schepers, J.M., Gropp, L. \& Geldenhuys, D.J. (2006). The factor structure, metrical properties, and convergent validity of the third edition (1999) of the Locus of Control Inventory. $S A$ Journal of Industrial Psychology, 32(2), 1 - 8.

Schmidke, A., Fricke, S., \& Lester, D. (1999). Suicide among German federal and state police officers. Psychological Reports, 84 (1), 157 - 166.

Sigel, I.E., \& Holmgren, A. (1983). A constructivist dialectic view of the development of a person: An update. In J. AdamsWeber and J.C. Mancuso (Eds), Applications of personal construct theory (pp. 55 - 72). Ontario: Academic.

Sims, A.C.P., \& Sims, D. (1998). The phenomenology of posttraumatic stress-disorder: A symptomatic study of 70 victims of psychological trauma. Psychopathology, 31(2), 96 -112 .

Spielberger, C. D. (1972). Anxiety: Current trends in theory and research. New York, N.Y.: Academic Press.

Spielberger, C. D. (1983). Manual for the State-Trait Anxiety Inventory (STAI). PaloAlto, CA: Consulting Psychologists Press.

VandenBos, G.R., \& Bulatao, E.Q. (1996). Violence on the job: Identifying risks and developing solutions. Washington, DC: American Psychological Association.

Van Dijk, J. (1996). Victim empowerment and support in an international perspective. In L. Camerer \& J. Nel, Putting Victims on the Agenda, Institute for Security Studies, Monograph Series, No. 7, pp. 18-30.

Violanti, J.M. (1996). Police suicide: Epidemic in blue. Springfield, IL, USA: Charles C. Thomas Publisher.

Violanti, J.M., Vena, J.E., \& Petralia, S. (1998). Mortality of a police cohort. American Journal of Industrial Medicine, 33(4), $366-373$

Wearing, A.J., \& Hart, P.M. (1996b). Work and non-work coping strategies: Their relation to personality, appraisal and life domain. Stress Medicine, 12(2), 93 - 103.

Welch, J. (1998). Life savers: IPD people management award 1998 special issue. People Management, 22, 46.

Wilson, F.C., Poole, A.D., \& Trew, K. (1997). Psychological distress in police officers following critical incidents. Irish Journal of Psychology, 18(3), 321 - 340.

Winter, D. (1985). Neurotic disorders: The curse of certainty. In E. Button (Ed.), Personal construct theory and mental health (pp. 103 - 131). Kent: Croom Helm. 